\title{
Interface of cancer stem cells and cancer immunity
}

\author{
Tomonari Kinoshita ${ }^{1,2}$, Yutaka Kawakami ${ }^{1,3}$ \\ ${ }^{1}$ Division of Cellular Signaling, Institute for Advanced Medical Research, ${ }^{2}$ Division of General Thoracic Surgery, Department of Surgery, Keio \\ University School of Medicine, Tokyo, Japan; ${ }^{3}$ Department of Immunology, School of Medicine, International University of Health and Welfare, \\ Chiba, Japan \\ Correspondence to: Yutaka Kawakami. Division of Cellular Signaling, Institute for Advanced Medical Research, Keio University School of Medicine, 35 \\ Shinanomachi, Shinjukuku, Tokyo 160-8582, Japan. Email: yutakawa@keio.jp; yutakawa@iuhw.ac.jp. \\ Provenance and peer review: This article was commissioned by the editorial office, Annals of Translational Medicine. The article did not undergo external \\ peer review. \\ Comment on: Masciale V, Grisendi G, Banchelli F, et al. Correlating tumor-infiltrating lymphocytes and lung cancer stem cells: a cross-sectional study. \\ Ann Transl Med 2019;7:619.
}

Submitted Mar 11, 2020. Accepted for publication Mar 30, 2020.

doi: $10.21037 / \mathrm{atm} .2020 .04 .08$

View this article at: http://dx.doi.org/10.21037/atm.2020.04.08

Immune checkpoint inhibitors have established their clinical position as the fourth primary treatment of nonsmall cell lung cancer (NSCLC) in addition to surgery, chemotherapy, and radiotherapy (1-3). However, not all patients received a survival benefit from the immunotherapies. Many researchers are attempting to reveal the underlying mechanisms, which may lead to development of novel biomarkers to predict the clinical outcome of the immunotherapy as well as novel therapeutic targets for immunotherapy (4). Infiltration of tumor reactive $\mathrm{CD}^{+} \mathrm{T}$ cells such as neo-antigen specific $\mathrm{CD} 8^{+}$ $\mathrm{T}$ cells in tumor tissues, and subsequent expression of programmed cell death ligand 1 (PD-L1) in tumor cells and other stromal cells induced by IFN- $\gamma$ from $\mathrm{T}$ cells, which indicates high immunogenicity of cancer cells, appear to be essential for PD-1/PD-L1 antibody monotherapy to work out. Therefore, the understanding of the factors influencing $\mathrm{CD}^{+}$tumor-infiltrating lymphocytes (TILs) is important.

Masciale et al. demonstrated the possible positive relationship between high aldehyde dehydrogenase (ALDH), lung cancer cells which may contain lung cancer stem cells (LCSCs) and TILs, particularly CD8 ${ }^{+} \mathrm{T}$ cells (5). The relationship between TILs and LCSCs has not been investigated well in lung cancer. In spite of its small numbers of the analyzed patients, this study would bring new insights into tumor immunology in lung cancer. However, this result seems to be contradictory to the previous reports. High concentration of TILs was reported to correlate with improved disease free survival and decreased risk of recurrence in lung cancer (6-9), whereas cancer stem cell (CSC) is generally linked to tumor recurrence and metastasis $(10,11)$. CD133 has been widely used as a CSC marker in NSCLC (12). A meta-analysis of 11 studies with total 1,004 NSCLC patients confirmed that high CD133 expression was correlated with significantly worse 5 -year overall survival than those with low CD133 expression. CD133 expression was also associated with various clinical parameters such as tumor stage, grade, differentiation status and lymph node metastasis $(13,14)$. Regarding its relationship with immune responses, Huang et al. reported that CD133 expression on lung cancer cells was negatively correlated with infiltration of $\mathrm{CD} 56^{+}$cells, but not of $\mathrm{CD} 8^{+}$ T cells (15). They speculated that CSC may not be able to initiate immune responses without help of other immune cells and cytokines, and that the immunosuppressive ability of CSCs may be dominant over the induction of anti-tumor immune responses. Indeed, several reports suggested that CSCs evolve strategies to evade from T-cell attacks $(16,17)$.

ALDH1 discussed in Masciale's study has emerged as one of the prominent markers for CSCs in various solid cancers including lung cancer (18). ALDH1 overexpression was associated with poor prognosis in NSCLC patients, where high ALDH1 expression was significantly associated with a more aggressive and advanced pathological grade and stage (19). Furthermore, increased ALDH1 expression has been associated with increased metastasis in multiple cancers (20). These results of CD133- or ALDH-related CSCs study may be contradictory to the Masciale's study. 


\section{Page 2 of 3}

Although ALDH1-positive cells are highly resistant to chemotherapeutic agents commonly used as first-line therapy in the clinical setting, such as cisplatin, gemcitabine, doxorubicin, vinorelbine and docetaxel (18), the relationship between ALDH1 positive cells and immune responses/ immunotherapies have not been elucidated.

$\mathrm{Li}$ et al. reported that positive ALDH1A1 (isoform of ALDH1) expression was correlated with patients' smoking status and advanced stage (21). Patel and colleagues revealed that ALDH1A1 and ALDH3A1 were upregulated in lung tissues as a result of exposure to carcinogenic aldehydes in cigarette smokers. Atypical pneumocytes expressed ALDH1A1 and ALDH3A1 significantly higher than normal pneumocytes, suggesting upregulation during malignant transformation to lung cancer (22). On the other hand, we have previously reported that NSCLC developed in smokers have higher numbers of $\mathrm{CD} 8^{+}$TILs than those in nonsmokers, and was correlated with better post-surgery prognosis (6). Although Masciale et al. enrolled only smokers with NSCLC, either adenocarcinoma or squamous carcinoma, environmental factors such smoking habit could have some influence on the relationship between CSCs and TILs.

Masciale et al. discussed one possibility that CSCs could stimulate $\mathrm{CD}^{+} \mathrm{T}$ cells specific for CSCs. Morita and their colleagues reported that $\mathrm{CD} 8^{+} \mathrm{T}$ cells specific tumor antigens such as cancer germ line antigens could be induced in multiple types of cancers such as colon cancers, and those CSC expressing such tumor antigens could be important therapeutic targets (23). However, CSCs may also express various immune-inhibitory molecules including PD-L1, and may evade from $T$ cell attack (15).

Another important point to be discussed is characteristics of $\mathrm{CD} 8^{+}$TILs. CD $8^{+} \mathrm{T}$ cells are important cytotoxic effector cells for tumor eradication in various types of cancers including NSCLCs. However, exhaustion of CD8 ${ }^{+}$ $\mathrm{T}$ cells that lost anti-tumor activity, or immunosuppressive $\mathrm{CD} 8^{+}$regulatory $\mathrm{T}$ cells (Tregs), might be induced possibly by ALDH positive CSCs. Actual function of CD8 ${ }^{+}$TILs and their correlation with prognosis have not been evaluated in Masciale's study. Kiniwa et al. reported that $\mathrm{CD} 8^{+}$Foxp $^{+}$T-cells had immunosuppressive activity similar to $\mathrm{CD}^{+} \mathrm{Foxp}^{+}$Tregs in prostate tumors (24). We also reported immunosuppressive CD $8^{+}$TILs including immunodysfunctional $\mathrm{CD} 8^{+} \mathrm{GATA}^{+}$or immunoregulatory $\mathrm{CD}^{+} \mathrm{FOXP}^{+} \mathrm{T}$ cells in lung adenocarcinoma (7). More detailed characterization of $\mathrm{CD}^{+}$TILs may provide new insights on this controversial issue. Additionally, Masciale et al.
Kinoshita and Kawakami. Interface of CSCs and cancer immunity

evaluated only 12 NSCLCs including 9 adenocarcinomas and 3 squamous cell carcinomas. More detailed studies on both histological types is required, because we reported that histological type would have a great influence on the subset status of TILs (6).

Nevertheless, the intriguing study by Masciale et al. may stimulate the field of the interfaces of cancer immunology and CSC biology, and we believe that further studies will reveal detailed interactions between CSCs and immune system and will lead to the development of new diagnostic and therapeutic strategies for patients with NSCLCs.

\section{Acknowledgments}

Funding: None.

\section{Footnote}

Conflicts of Interest: Both authors have completed the ICMJE uniform disclosure form (available at http://dx.doi. org/10.21037/atm.2020.04.08). The authors have no conflicts of interest to declare.

Ethical Statement: The authors are accountable for all aspects of the work in ensuring that questions related to the accuracy or integrity of any part of the work are appropriately investigated and resolved.

Open Access Statement: This is an Open Access article distributed in accordance with the Creative Commons Attribution-NonCommercial-NoDerivs 4.0 International License (CC BY-NC-ND 4.0), which permits the noncommercial replication and distribution of the article with the strict proviso that no changes or edits are made and the original work is properly cited (including links to both the formal publication through the relevant DOI and the license). See: https://creativecommons.org/licenses/by-nc-nd/4.0/.

\section{References}

1. Borghaei H, Paz-Ares L, Horn L, et al. Nivolumab versus Docetaxel in Advanced Nonsquamous Non-Small-Cell Lung Cancer. N Engl J Med 2015;373:1627-39.

2. Ettinger DS, Aisner DL, Wood DE, et al. NCCN Guidelines Insights: Non-Small Cell Lung Cancer, Version 5.2018. J Natl Compr Canc Netw 2018;16:807-21.

3. Brahmer J, Reckamp KL, Baas P, et al. Nivolumab versus Docetaxel in Advanced Squamous-Cell Non-Small-Cell 
Lung Cancer. N Engl J Med 2015;373:123-35.

4. Rizvi NA, Hellmann MD, Snyder A, et al. Cancer immunology. Mutational landscape determines sensitivity to PD-1 blockade in non-small cell lung cancer. Science 2015;348:124-8.

5. Masciale V, Grisendi G, Banchelli F, et al. Correlating tumor-infiltrating lymphocytes and lung cancer stem cells: a cross-sectional study. Ann Transl Med 2019;7:619.

6. Kinoshita T, Muramatsu R, Fujita T, et al. Prognostic value of tumor-infiltrating lymphocytes differs depending on histological type and smoking habit in completely resected non-small-cell lung cancer. Ann Oncol 2016;27:2117-23.

7. Kinoshita T, Kudo-Saito C, Muramatsu R, et al. Determination of poor prognostic immune features of tumour microenvironment in non-smoking patients with lung adenocarcinoma. Eur J Cancer 2017;86:15-27.

8. Kanwal B, Biswas S, Seminara RS, et al. Immunotherapy in Advanced Non-small Cell Lung Cancer Patients: Ushering Chemotherapy Through the Checkpoint Inhibitors? Cureus 2018;10:e3254.

9. Brahmer JR, Govindan R, Anders RA, et al. The Society for Immunotherapy of Cancer consensus statement on immunotherapy for the treatment of non-small cell lung cancer (NSCLC). J Immunother Cancer 2018;6:75.

10. Moharil RB, Dive A, Khandekar S, et al. Cancer stem cells: An insight. J Oral Maxillofac Pathol 2017;21:463.

11. Ciurea ME, Georgescu AM, Purcaru SO, et al. Cancer stem cells: biological functions and therapeutically targeting. Int J Mol Sci 2014;15:8169-85.

12. Eramo A, Lotti F, Sette G, et al. Identification and expansion of the tumorigenic lung cancer stem cell population. Cell Death Differ 2008;15:504-14.

13. Qu H, Li R, Liu Z, et al. Prognostic value of cancer stem cell marker CD133 expression in non-small cell lung cancer: a systematic review. Int J Clin Exp Pathol 2013;6:2644-50.

14. Wang $\mathrm{W}$, Chen $\mathrm{Y}$, Deng J, et al. The prognostic value of CD133 expression in non-small cell lung cancer: a meta-

Cite this article as: Kinoshita T, Kawakami Y. Interface of cancer stem cells and cancer immunity. Ann Transl Med 2020;8(13):810. doi: 10.21037/atm.2020.04.08 analysis. Tumour Biol 2014;35:9769-75.

15. Huang $\mathrm{Z}, \mathrm{Yu} \mathrm{H}$, Zhang J, et al. Correlation of cancer stem cell markers and immune cell markers in resected nonsmall cell lung cancer. J Cancer 2017;8:3190-7.

16. Volonte A, Di Tomaso T, Spinelli M, et al. Cancerinitiating cells from colorectal cancer patients escape from T cell-mediated immunosurveillance in vitro through membrane-bound IL-4. J Immunol 2014;192:523-32.

17. Schatton T, Schutte U, Frank NY, et al. Modulation of T-cell activation by malignant melanoma initiating cells. Cancer Res 2010;70:697-708.

18. Jiang F, Qiu Q, Khanna A, et al. Aldehyde dehydrogenase 1 is a tumor stem cell-associated marker in lung cancer. Mol Cancer Res 2009;7:330-8.

19. Okudela K, Woo T, Mitsui H, et al. Downregulation of ALDH1A1 expression in non-small cell lung carcinomas-its clinicopathologic and biological significance. Int J Clin Exp Pathol 2013;6:1-12.

20. Sullivan JP, Spinola M, Dodge M, et al. Aldehyde dehydrogenase activity selects for lung adenocarcinoma stem cells dependent on notch signaling. Cancer Res 2010;70:9937-48.

21. Li X, Wan L, Geng J, et al. Aldehyde dehydrogenase 1A1 possesses stem-like properties and predicts lung cancer patient outcome. J Thorac Oncol 2012;7:1235-45.

22. Patel M, Lu L, Zander DS, et al. ALDH1A1 and ALDH3A1 expression in lung cancers: correlation with histologic type and potential precursors. Lung Cancer 2008;59:340-9.

23. Morita R, Hirohashi Y, Torigoe T, et al. Olfactory Receptor Family 7 Subfamily C Member 1 Is a Novel Marker of Colon Cancer-Initiating Cells and Is a Potent Target of Immunotherapy. Clin Cancer Res 2016;22:3298-309.

24. Kiniwa Y, Miyahara Y, Wang HY, et al. CD8+ Foxp3+ regulatory $\mathrm{T}$ cells mediate immunosuppression in prostate cancer. Clin Cancer Res 2007;13:6947-58. 